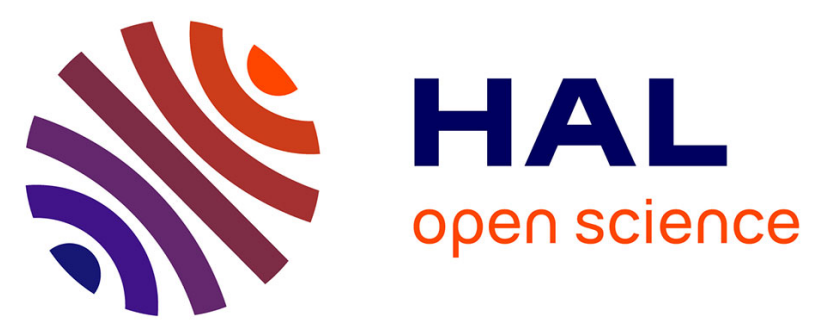

\title{
Detection of manhole covers in high-resolution aerial images of urban areas by combining two methods
}

Jérôme Pasquet, Thibault Desert, Olivier Bartoli, Marc Chaumont, Carole Delenne, Gérard Subsol, Mustapha Derras, Nanée Chahinian

\section{To cite this version:}

Jérôme Pasquet, Thibault Desert, Olivier Bartoli, Marc Chaumont, Carole Delenne, et al.. Detection of manhole covers in high-resolution aerial images of urban areas by combining two methods. JURSE: Joint Urban Remote Sensing Event, Mar 2015, Lausanne, Switzerland. lirmm-01234242

\section{HAL Id: lirmm-01234242 \\ https://hal-lirmm.ccsd.cnrs.fr/lirmm-01234242}

Submitted on 3 Dec 2015

HAL is a multi-disciplinary open access archive for the deposit and dissemination of scientific research documents, whether they are published or not. The documents may come from teaching and research institutions in France or abroad, or from public or private research centers.
L'archive ouverte pluridisciplinaire HAL, est destinée au dépôt et à la diffusion de documents scientifiques de niveau recherche, publiés ou non, émanant des établissements d'enseignement et de recherche français ou étrangers, des laboratoires publics ou privés. 


\title{
Detection of manhole covers in high-resolution aerial images of urban areas by combining two methods
}

\author{
PASQUET J.*‡, DESERT T. ${ }^{\dagger}$, BARTOLI O. ${ }^{\dagger}$, CHAUMONT M..$^{\ddagger}$, DELENNE C..$^{\uparrow}$, \\ SUBSOL G. ${ }^{\ddagger}$, DERRAS M.* and CHAHINIAN N. ${ }^{\dagger}$ \\ Email: pasquet@lirmm.fr \\ *Berger-Levrault, Labège, France \\ †IRD, UMR HSM 5569 (CNRS, IRD, Université de Montpellier), France \\ $\S$ Université de Nîmes, France \\ $\ddagger$ LIRMM, Université de Montpellier / CNRS, France \\ ๆ Université de Montpellier, UMR HSM 5569 (CNRS, IRD, Université de Montpellier), France
}

\begin{abstract}
The detection of small objects from aerial images is a difficult signal processing task. To localise small objects in an image, low-complexity geometry-based approaches can be used, but their efficiency is often low. Another option is to use appearance-based approaches that give better results but require a costly learning step. In this paper, we treat the specific case of manhole covers. Currently many manholes are not listed or are badly positioned on maps. We implement two conventional previously published methods to detect manhole covers in images. The first one searches for circular patterns in the image while the second uses machine learning to build a model of manhole covers. The results show non optimal performances for each method. The two approaches are combined to overcome this limit, thus increasing the overall performance by about forty percent.
\end{abstract}

\section{INTRODUCTION}

Urban growth is an ongoing trend and one of its direct consequences is the development of underground utility networks. Over the past century it was common practice for public service providers to install, operate and repair their networks separately [6], so it is now very difficult to find accurate records of utility network maps in cities in both industrialized and developing countries. This crucial problem will worsen as cities expand and their networks increase in size and complexity [2] [3]. Urban works will thus be more prone to delays with concomitant additional costs [9] [10]. However, some of these networks have surface access traps which may be visible on airborne or satellite images. If correctly detected, these elements could serve as indicators of underground utility networks. Furthermore, they can be used as landmarks in photogrammetric applications [11] or in geotechnical works such as subsidence calculations [8]. We put forward a methodology to detect small urban objects, namely manhole covers and grates, on very high-resolution aerial and satellite images. Two methods are tested. The first is based on a geometrical circular filter whereas the second uses machine learning to retrieve some patterns. The results are compared and combined in order to benefit from the two approaches.

\section{Methods}

\section{A. Circular detection filter}
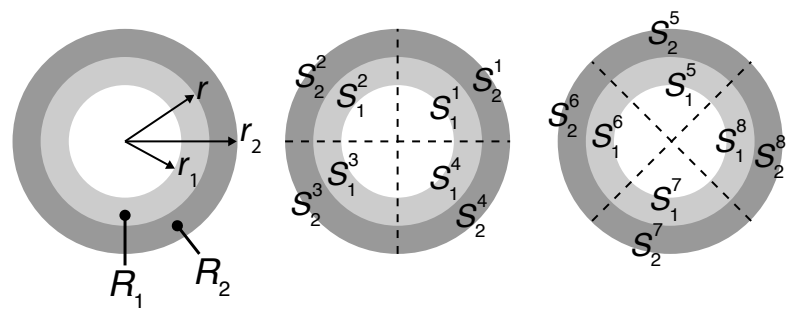

Fig. 1. Circular filter (from [4]). Left: $R_{1}$ and $R_{2}$ are the two main regions; middle and right: definition of the subregions (the phase shift is $\pi / 4$ ).

The geometrical approach is based on the method proposed in [4] for the detection of circular patterns in a noisy and low contrasted image. The authors propose a filter that consists of two annular regions $R_{1}$ and $R_{2}$ of radius $r_{1}$ to $r$ and $r$ to $r_{2}$, each of which is divided into eight sub-regions (see Figure 1). The filter is applied to a grey-scaled image, obtained with the luminance formula. Three indices are computed to detect a circular pattern on a sliding window, using normalized histograms of each region/subregion.

The first one estimates the similarity between two statistical distributions using the Bhattacharyya coefficient:

$$
\mathrm{S}\left(R_{1}, R_{2}\right)=\sum_{x=0}^{N} \sqrt{p_{1}(x) p_{2}(x)}
$$

with $p_{1}$ (respectively $p_{2}$ ) being the normalized histogram of $R_{1}$ (respectively $R_{2}$ ) and $N$ the maximal intensity of the two histograms. The result of this index is 1.0 when the two histograms are identical and 0.0 when they are completely different. The optimal value for this index in case of a circular pattern is thus the lowest one.

The second index is computed to avoid detection of linear patterns. It is based on a comparison between intensity distributions of $R_{1}$ and the eight sub-regions of $R_{2}$ :

$$
\mathrm{S}_{8}=\max _{j \in 1 \ldots 8}\left\{\mathrm{~S}\left(R_{1}, S_{2}^{j}\right)\right\}
$$


where $S_{2}^{j}$ denotes the $j^{\text {th }}$ subregion of $R_{2}$. This index is low when all oriented similarity scores between $R_{1}$ and $R_{2}$ subregions are small.

The last index assesses the uniformity inside the two main regions:

$$
\mathrm{U}\left(R_{i}\right)=\min _{j, j^{\prime} \in\{1 . .8\}}\left\{\mathrm{S}\left(S_{i}^{j}, S_{i}^{j^{\prime}}\right)\right\}
$$

where $i$ stands for the region and $j, j^{\prime}$ for the subregions.

The three indexes are merged in a global index for circular pattern detection:

$$
\zeta=\left(1-\max \left\{\mathrm{S}\left(R_{1}, R_{2}\right), \mathrm{S}_{8}\right\}\right) \cdot \mathrm{U}\left(R_{1}\right) \cdot \mathrm{U}\left(R_{2}\right)
$$

The greater the value of $\zeta$, the higher the likelihood of a circular pattern.

\section{B. Machine learning approach}

The appearance approach uses a machine learning algorithm which builds a model from data. This method is quite efficient for urban object detection [12]. The learning step involves in three stages [7]. 1) We extract small images of manhole covers and small random images from the training database. Each small image is resized to a constant size in order to be robust to all scale. 2) To transform the data to a feature vector, we extract multiple histograms from oriented gradients (HOG) [5]. Each HOG vector measures the distribution of the gradient angles within the image. 3) The final step consists in using a linear SVM classifier [1] to create the required model.

During the evaluation step, a sliding window evaluates all the positions and scales in the entire image.

\section{Merging the approaches}

There is a marked difference between the two approaches. The first one uses only pixel intensity while the second one uses a robust model that is built from the gradient. We experimentally observed that the false positives varied from one approach to the other. Therefore, we combined the results from the two methods to increase the detection performance. The final score is obtained by merging the scores given by each approach.

Let $f(x)$ be a function that returns the value of $\zeta$ for a pixel $x$ (Eq.4) rescaled between 0 and 100, and $g(x)$ is a function that returns the probability of a pixel $x$ being a manhole cover center by the machine learning approach. The product function between $f$ and $g$ is called $h$ (Eq. 5) and is used as a score value for the presence of manhole covers.

Note that all the objects may not be detected by both methods. For instance, function $f$ returns a null score for rectangular shapes. We thus suggest other functions for scoring the presence of a manhole cover, $s(x)$ for the sum (Eq. 6), $n(x)$ and $m(x)$ for the min and max (Eqs. 8 and 7). Scoring functions are evaluated in the experimental section III.

$$
\begin{gathered}
h(x)=f(x) \cdot g(x) \\
s(x)= \begin{cases}2 \cdot f(x) & g(x)=0 \\
2 . f(x) & f(x)=0 \\
f(x)+g(x) & \text { otherwise }\end{cases}
\end{gathered}
$$

$$
\begin{gathered}
m(x)=\max (f(x), g(x)) \\
n(x)=\min (f(x), g(x))
\end{gathered}
$$

The results are compared in terms of precision and recall:

$$
\begin{gathered}
\text { precision }=\frac{\mathrm{TP}}{\mathrm{TP}+\mathrm{FP}} \\
\text { recall }=\frac{\mathrm{TP}}{\mathrm{TP}+\mathrm{FN}}
\end{gathered}
$$

with TP: true positive (number of correctly detected manhole covers); FN: false negative (number of omitted manhole covers); FP: false positive (number of objects confused as manhole covers).

\section{EXPERIMENTAL RESULTS}

\section{A. Data sets}

The methods were tested on a orthorectified aerial photograph $(5,300 \times 5,500$ pixels at $4 \mathrm{~cm}$ resolution) of the town of Gigean in the South of France (see Figure 2). The scene contained 125 manholes, with an average size of $80 \times 80 \mathrm{~cm}$, 91 of which were used to build the training set and 34 were used for the testing step. Before any localisation treatment, the image was firstly segmented and only pixels from the road and street networks were used.

\section{B. Evaluation with and without machine learning}

Figure 3.a illustrates the performance of the circular detection filter method using a ROC curve (precision as a function of the recall) where the threshold applied to $\zeta$ varies. All manhole covers could not be detected by this method because about $20 \%$ of them had a rectangular shape and were undetectable. We also noticed a significant number of false positives. In fact, there were many circular patterns on the road. Which were oil spots or potholes and they were enhanced as the image is smoothed.

The ROC curve of the machine learning method, which has higher precision than the previous method, is plotted in Figure 3.b. Nevertheless, poor results were obtained; for a recall of $50 \%$, only $20 \%$ of the objects were manhole covers. The poor results could stem from the small size of the training database.

\section{Combined method}

Figure 4 illustrates the combined method, with functions $H, M, N$, which was more efficient than the separate approaches presented in section II. All the fusing methods except the one using the $s(x)$ function gave better results than each method taken separately, as can be seen in Figure 5. The poorer results obtained with the summing function $s(x)$ were due to the addition of all detections, including false ones. Hence, the precision was worsened according to Eq. 9.

With the remaining functions $(m(x), n(x)$ and $h(x))$, the precision was increased by more than $25 \%$. For instance, a recall of $40 \%$ corresponded to a precision of approximately $43 \%$ for the machine learning approach ( $M L$ curve) and reached $68 \%$ for the min function ( $N$ curve). 


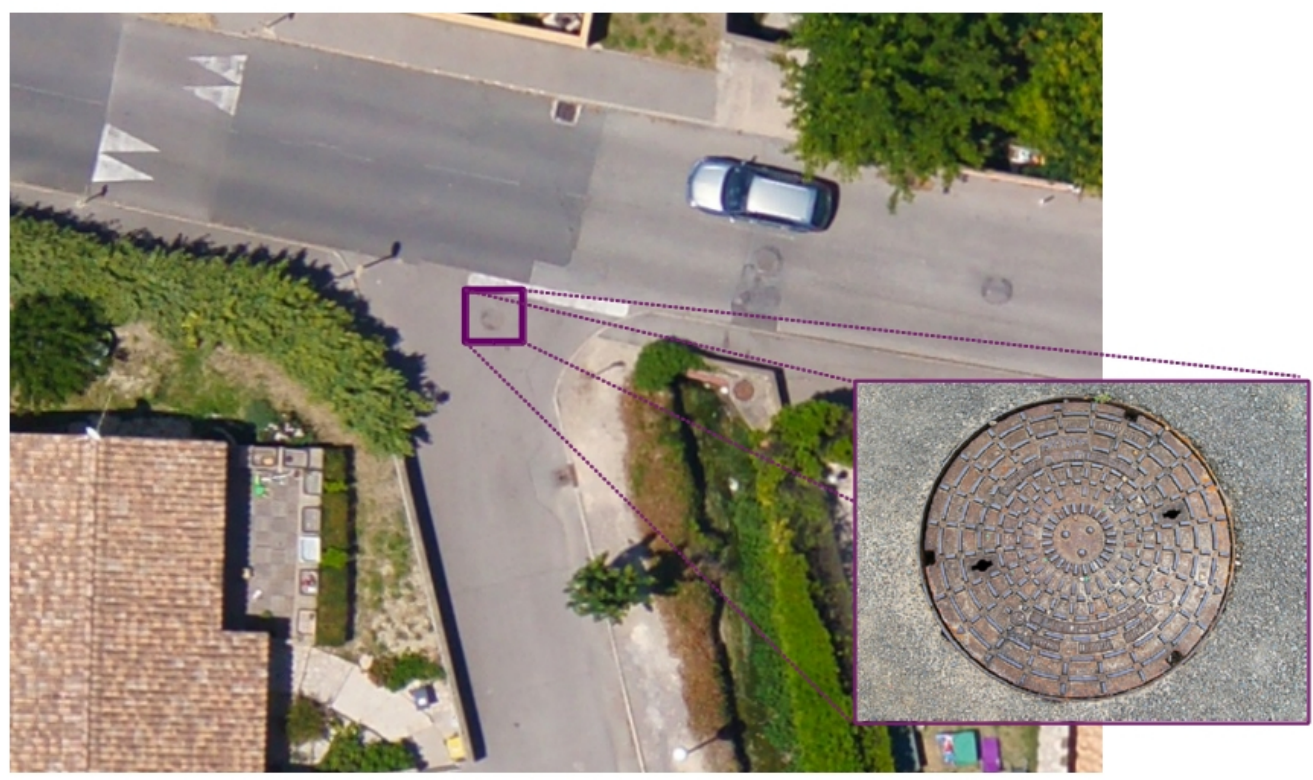

Fig. 2. Sample image with at $4 \mathrm{~cm}$ resolution on which we performed learning step.

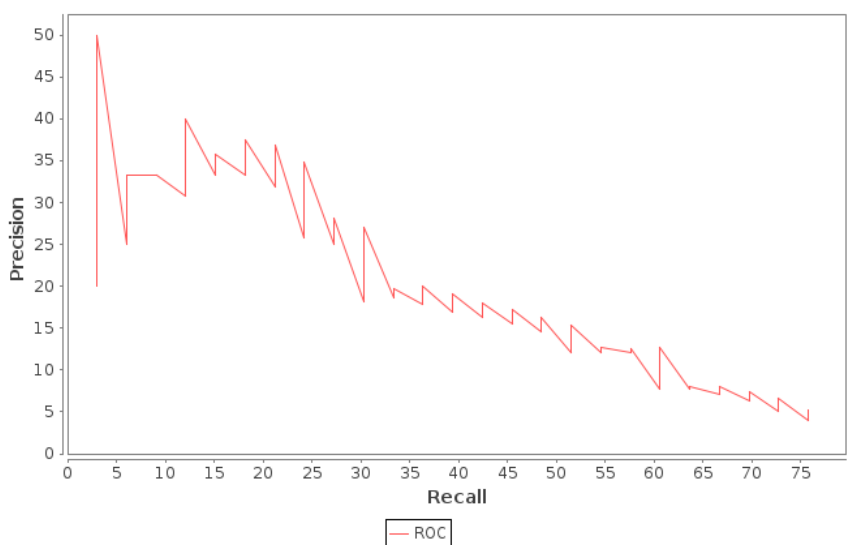

(a)

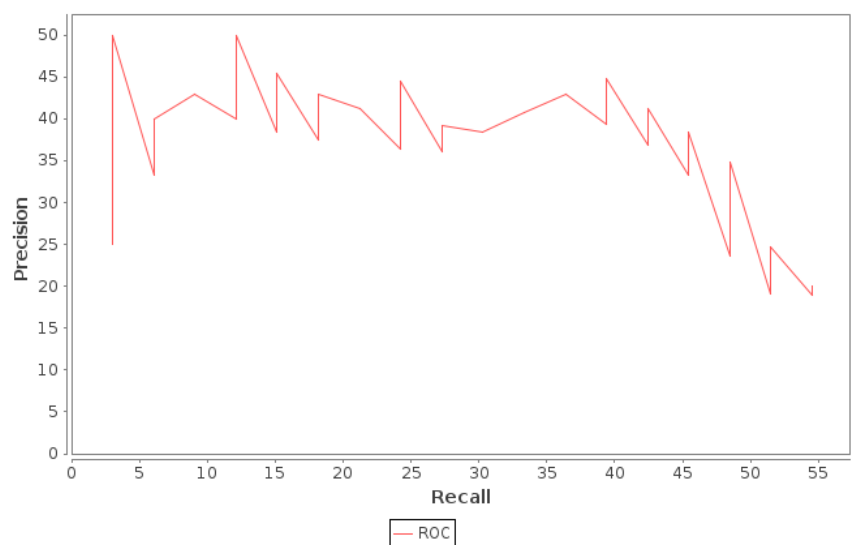

(b)

Fig. 3. Precision vs recall. a) with circular pattern detection; b) with the machine learning method.

We noticed that the maximum function $m(x)$ gave a better score: nearly twice the precision of the machine learning method. Actually, if the classifier probability value is high, then this response is more efficient than the dot or minimum return. This could have two explanations. First, nearly ideal circular shapes may be detected with high precision by the circular filter, but may have a lower probability with the machine learning method, which has no information on the shape. In contrast, the circular filter gives a lower score for rectangular manhole covers, contrary to the machine learning approach, which is more robust.

The main shortcomings of this kind of approach is that, when using two methods, the combined recall value is always lower than the lowest score of each method taken separately.

\section{CONCLUSION}

The objective of this work was to put forward a methodology to detect small urban objects on high resolution images in order to reconstruct buried utility networks. The first case study on a sewage network is highly encouraging, especially considering that we had a small training set, which was used for the machine learning method. The preliminary results show that nearly $40 \%$ of manhole covers were detected with a precision of $80 \%$. This compares well with the common practice of field surveyors in southern France, who are frequently asked to locate only one third of manhole covers in order to cut down operational costs. Many options remain unexplored and will be investigated in the very near future. For instance, a square filter could be added to the geometrical detection procedure, additional SVMs could be tested as well as other combined methods. The high resolution of the aerial images for the localisation of small urban objects is a highly promising research field.

\section{REFERENCES}

[1] R. Fan, K. Chang, C. Hsieh and C. Lin ,'LIBLINEAR: A Library for Large Linear Classification", Journal of Machine Learning Research, Vol. 


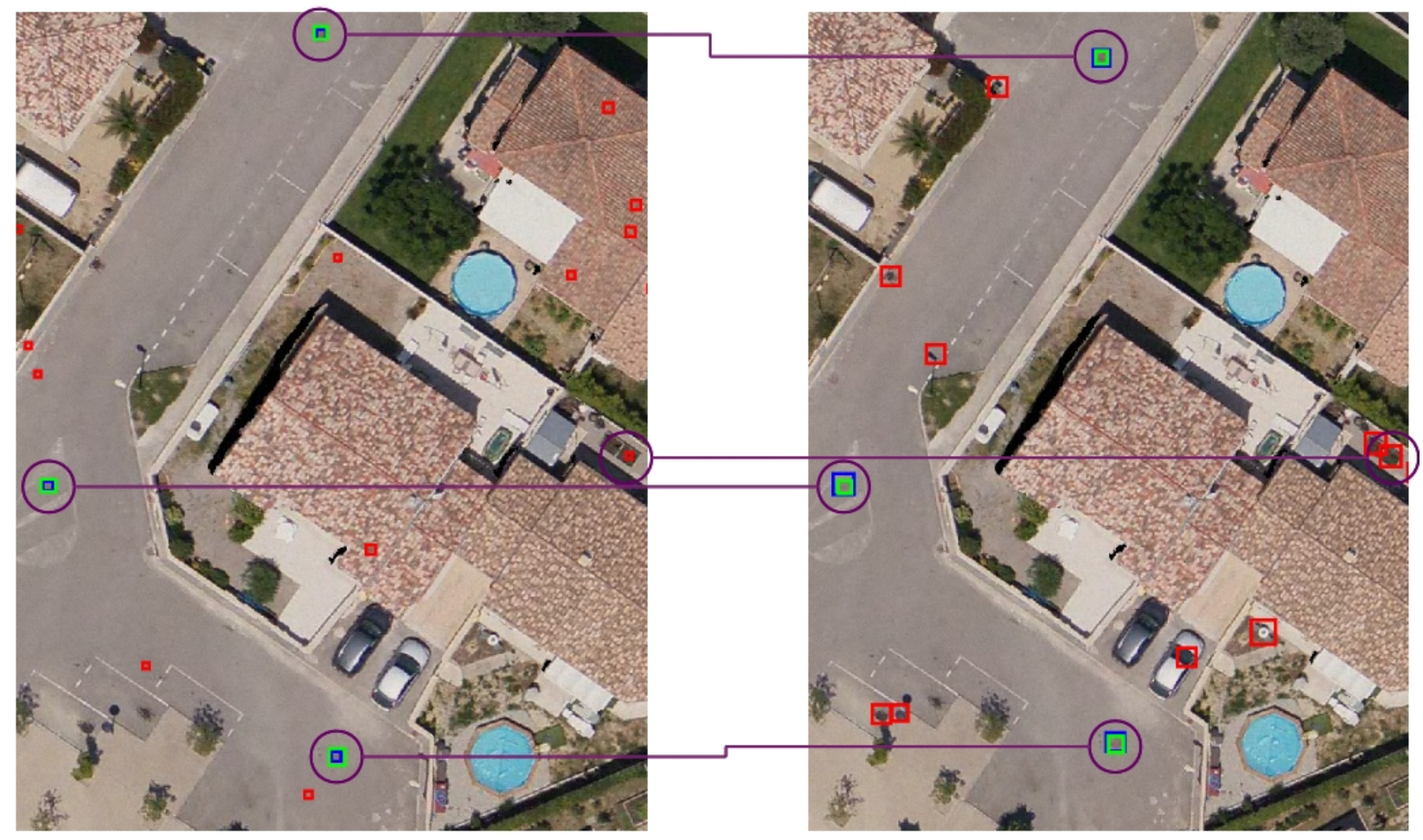

Fig. 5. The two figures represent the results obtained with the circular filter on the left and the machine learning method on the right. The red rectangles are the true negatives, the blue rectangles are the true positives and the green rectangles are the ground truth. The lines connect the two common results between two approaches. The testing image is at $4 \mathrm{~cm}$ resolution.

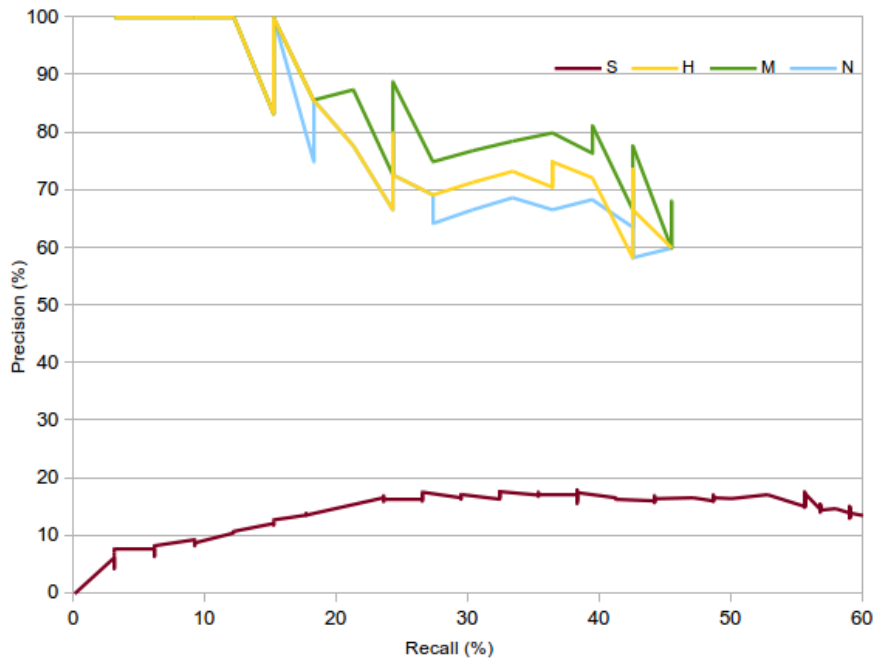

Fig. 4. Results of the combined method: summing (s), dot (h), maximum (m) and minimum (n) functions. Comparison with both approaches (ML-machine learning) and (CF-circular filter)

\section{9, 2008, pp. 1871-1874}

[2] H. Jamil, Z. Nomanbhoyn, and M.Y. Mohid Yussof, "Underground utility mapping and its challenges in Malaysia", FIG working week 2012. Knowing to manage the territory, protect the environment, evaluate the cultural heritage, Rome, Italy, 6-10 May 2012, pp. 15.

[3] N. Metje, P. Atkins, M. Brennan, D. Champan, H. Lim, J. Machell, J. Muggleton, S. Pennock, J. Ratcliffe, M. Redfern, C. Rogers, A. Saul, Q. Shan, S. Swingler, A. Thomas. "Mapping the underworld: State of the art review.", Tunnelling and underground space technology, 2007, 568-586.
[4] H. Niigaki, J. Shimamura and M. Morimoto, "Circular Object Detection Based on Separability and Uniformity of Feature Distributions using Bhattacharyya Coefficient", In: Proceedings of International Conference on Pattern Recognition, 2012, pp. 2009-2012.

[5] Q. Qiang, S. Avidan, M. Yeh and K. Cheng, "Fast Human Detection Using a Cascade of Histograms of Oriented Gradients", In: Proceedings of Computer Vision and Pattern Recognition, 2006, pp. 1491-149

[6] Rogers, C. D. F. and Hao, T. and Costello, S. B. and Burrow, M. P. N. and Metje, N. and Chapman, D. N. ... and Saul, A. J. Condition assessment of the surface and buried infrastructureA proposal for integration. Tunnelling and Underground Space Technology, 2012, 28, 202-211.

[7] P. Viola and M. Jones,"Rapid Object Detection using a Boosted Cascade of Simple Features", In: Proceedings of Computer Vision and Pattern Recognition, 2001, pp. 511-518

[8] G. Liu, H. Jia, R. Zhang, H. Zhang, H. Jia, B. Yu and M. Sang, "Exploration of subsidence estimation by persistent scatterer InSAR on time series of high resolution TerraSAR-X images." Selected Topics in Applied Earth Observations and Remote Sensing, IEEE Journal, 2011, 4(1): $159-170$.

[9] Y. Yung. Evaluation of subsurface utility engineering for highway projects: benefit-cost analysis. Tunnelling and underground space technology, 2012, 27: 111-122.

[10] H. Jeong, D. Abraham and J. Lew. Evaluation of an emerging market in suburface utility engineering. Journal of construction engineering and management, 2004, 130(2): 225-234.

[11] C. Drewniok and K. Rohr. Exterior orientation-an automatic approach based on fitting analytic landmark models. ISPRS Journal of Photogrammetry and Remote Sensing, 1997, 52: 132-145.

[12] M. Chaumont, L. Tribouillard, G. Subsol, F. Courtade, J. Pasquet and M. Derras. Automatic localization of tombs in aerial imagery: application to the digital archiving of cemetery heritage. Digital Heritage - International Congress, 2013, 1: 657-660. 